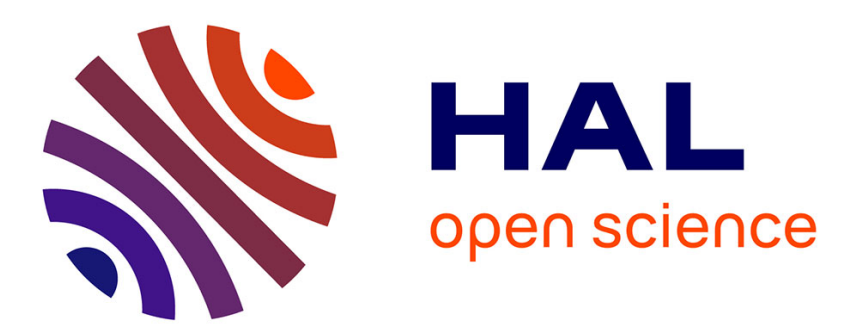

\title{
Enhancing fluorescence in vivo imaging using inorganic nanoprobes
}

\author{
S Bouccara, G Sitbon, A Fragola, V Loriette, N Lequeux, T Pons
}

\section{To cite this version:}

S Bouccara, G Sitbon, A Fragola, V Loriette, N Lequeux, et al.. Enhancing fluorescence in vivo imaging using inorganic nanoprobes. Current Opinion in Biotechnology, 2015, 34, pp.65 - 72. 10.1016/j.copbio.2014.11.018 . hal-01100022

\section{HAL Id: hal-01100022 \\ https://hal.science/hal-01100022}

Submitted on 5 Jan 2015

HAL is a multi-disciplinary open access archive for the deposit and dissemination of scientific research documents, whether they are published or not. The documents may come from teaching and research institutions in France or abroad, or from public or private research centers.
L'archive ouverte pluridisciplinaire $\mathbf{H A L}$, est destinée au dépôt et à la diffusion de documents scientifiques de niveau recherche, publiés ou non, émanant des établissements d'enseignement et de recherche français ou étrangers, des laboratoires publics ou privés. 


\title{
Enhancing fluorescence in vivo imaging using inorganic nanoprobes
}

\author{
S. Bouccara, ${ }^{\S, a, b, c}$ G. Sitbon, ${ }^{\S, a, b, c}$ A. Fragola, ${ }^{a, b, c}$ V. Loriette, ${ }^{a, b, c}$ N. Lequeux, ${ }^{a, b, c}$ T. Pons ${ }^{*, a, b, c}$ \\ a LPEM, PSL Research University, ESPCI-ParisTech, 10 rue Vauquelin, F-75231 Paris Cedex 5, France \\ ${ }^{b}$ CNRS, UMR 8213, F-75005 Paris, France \\ ' Sorbonne Universités, UPMC Univ Paris 06, F-75005 Paris, France \\ $\S$ These authors contributed equally to this manuscript \\ * corresponding author: thomas.pons@espci.fr
}

\begin{abstract}
Fluorescence imaging is a versatile tool for biological and preclinical studies with steady improvements in performance thanks to instrumentation and probe developments. The sensitive detection and imaging of deep targets in vivo is especially challenging due to the diffusion and absorption of light by the tissues and to the emission of autofluorescence from intrinsic chromophores. Fluorescent inorganic nanoparticles present interesting optical properties that may significantly differ from organic dyes. In this short review, we present recent developments in the design of these nanoprobes and their use for new in vivo fluorescence modalities which provide enhanced imaging capabilities.
\end{abstract}

\section{Introduction}

Fluorescence in vivo imaging is becoming a commonly used tool to study biological functions and pathologies in living model organisms, and is being increasingly developed for clinical diagnostics and treatment. [1] Fluorescence imaging typically offers access to tissues a few $\mathrm{mm}$ or $\mathrm{cm}$ below the surface. It also offers unique advantages that make it a precious, powerful and very popular technique. Besides its ease of use, low cost, noninvasiveness and absence of ionizing radiation, it possesses distinct performance characteristics. For example, it offers high sensitivity, down to the single molecular tracer, as well as straightforward multiplexing capabilities by selecting probes with different spectral properties. It can also reach unrivaled spatial and temporal resolutions. For these reasons, in vivo fluorescence imaging techniques and applications are being developed at an accelerating pace. Several organic chromophores are being used in small animal models and in clinical applications. [1-4] In general however, for these dyes, the maximum imaging depth, resolution and sensitivity are limited by the optical properties of the tissues.[5] More specifically, the major obstacles limiting imaging performance are the absorption and diffusion of excitation and emission photons, causing a loss of signal and resolution, and the emission of autofluorescence from intrinsic chromophores, giving rise to spurious background signal. Inorganic nanoparticles, on the other hand, present unique optical properties that help alleviate some of these limitations. In this short review, we do not aim to offer a comprehensive review on fluorescent nanoparticles (NPs), but instead we will focus on how their optical properties can be used to enhance the performance of fluorescence in vivo imaging. 


\section{Near infrared emitting nanoprobes for in vivo imaging}

The near infrared window (700-1300 nm) enables deeper imaging thanks to reduced light absorption and scattering compared to the visible range, where intrinsic chromophores such as hemoglobin absorb, and to longer NIR wavelengths, where water and lipids strongly absorb. In addition, autofluorescence from intrinsic chromophores is strongly reduced when exciting and/or detecting in the NIR range. Two near infrared bands are usually distinguished, NIR I (700-950 nm) and NIR II (1000-1300 nm). Several classes of organic fluorophores emit in the NIR I band; indocyanine green, for example, is used for angiography. [6] Even though continuing progress is being made in the synthesis of brighter and more stable organic dyes, [2] nanoparticles offer interesting alternatives as NIR I-emitting probes. These include semiconductor quantum dots (QDs), metal nanoclusters, rare earth doped nanoparticles (RE-NPs) and nanodiamonds (NDs). After initial demonstrations of in vivo imaging based on CdTe and PbS materials, new generations of low toxicity NIR emitting QDs have emerged. [7] These are mainly composed of Culn(S/Se) 2 , [8-11] Cu-doped InP, [12] InAs, [13-16] and $\mathrm{Ag}_{2} \mathrm{~S}[17,18]$ nanocrystals. These QDs offer a high brightness thanks to their high extinction coefficient and quantum yields (QY), and a higher photostability compared to organic chromophores. Their emission is tunable with their size and composition. Metal nanoclusters are a novel class of fluorescent nanomaterials. While the exact underlying photophysical mechanism is not completely elucidated yet, NIR emitting gold nanoclusters have been synthesized. [19-22] These clusters are not as bright in terms of extinction coefficient and quantum yield as QDs, but their small size and lack of toxicity make them an attracting alternative. Carbon-based materials also present interesting optical properties. In particular, N-V centers in nanodiamonds (NDs) fluoresce in the far red-NIR range. [23, 24] These NDs are inert, which leads to a superior photostability and low toxicity. Finally, the fluorescence properties of rare earth doped nanoparticles rely on $4 \mathrm{f}$ transitions of trivalent lanthanide ions inserted in a suitable host matrix. The optical properties of these RE-NPs are therefore tunable by choosing appropriate emissive and sensitizing dopants. The choice of the host materials is determinant for the size control during the synthesis, as well as for the optical properties and colloidal and chemical stability. [25]

Surface chemistry of these different nanoprobes is of course crucial to guarantee their colloidal stability, preserve their optical properties in vivo, reduce non specific adsorption and provide specific targeting and functionality. The development of optimized chemistries is an ongoing research effort, which has already allowed most of these NPs to be used in small animals for different imaging applications. These include vasculature [26, 27] and lymph node [10] imaging, tumor detection [14], cell tracking $[28,29]$ and cell lineage. [30] In addition to providing higher detection sensitivity compared to standard NIR I organic fluorophores, these nanoprobes share several unique features. Their large hydrodynamic size, while restricting diffusion into tissues and preventing renal excretion above $5 \mathrm{~nm}$, [31] also extends the circulation time in the bloodstream and limit leaching from the blood vessels into surrounding tissues, leading to more specific targeting. In addition, tumor detection using nanoprobes benefits from the enhanced permeation and retention (EPR) effect:[32] nanoparticles in the 50-150 $\mathrm{nm}$ size range can penetrate loose epithelial barriers and remain much longer in the tumor than smaller organic dyes which get washed away much faster. [33] Similarly, endocytosed NPs tend to remain much longer inside targeted cells compared to smaller organic dyes, facilitating long term cell tracking. [34] In contrast to monofunctional organic dyes, the large surface of NPs can be used to assemble different components on a single nanoplatform. This potentially 
enhances the targeting efficiency, thanks to the multiplicity of targeting moieties, or provides multifunctional NPs carrying different targeting probes, drugs, contrast agents for complementary imaging modalities, and/or environment reporters. Interestingly, these nanoprobes also offer optical properties that can be exploited to develop new improved imaging modalities in terms of accessible depth, resolution and sensitivity. In the following sections, we will more specifically review recent developments of NPs that emit in the NIR II range, undergo efficient nonlinear excitation, present slow fluorescence decays for time-gated detection or can be efficiently coupled to other imaging modalities.

\section{NIR II emitting nanoprobes}

In vivo imaging in the NIR II band has long remained difficult due to the absence of fluorophores and sensitive detectors in this region. In principle however, the NIR II band offer several advantages compared to NIR I, including better detection sensitivity, thanks to a much lower autofluorescence background, and better spatial resolution deep in tissues, thanks to reduced light scattering. [35] In addition, NIR II probes can usually be excited in the NIR I band, which reduces photodamage and improves the excitation penetration. Water soluble NIR II organic dyes are not available so far, and the QY of their hydrophobic counterparts is limited to a few percents in organic solvents. [36] For these reasons, three main classes of NIR II nanoprobes are being actively developed (see Table 1). Single wall carbon nanotubes (SWNT) present a broad series of emission peaks between 1,000 and 1,400 nm. [37-40] RE-NPs can be designed to emit at different wavelengths in the NIR II band, from $1,200 \mathrm{~nm}\left(\mathrm{Er}^{3+}\right)$ to $1,525 \mathrm{~nm}\left(\mathrm{Pr}^{3+}\right)$. [41] $\mathrm{Ag}_{2} \mathrm{~S}$ and $\mathrm{Ag}_{2} \mathrm{Se}$ QDs have been synthesized with tunable spectra up to $1,300 \mathrm{~nm}$ and good quantum yields. [18, 42-45] In addition, the high chemical stability of $\mathrm{Ag}_{2} \mathrm{~S}$ reduces significantly the potential toxicity of these QDs, compared to other QD materials. These nanoprobes have been used for blood vessel imaging. The Dai group in particular, demonstrated that carbon nanotubes could provide images of cerebral vasculature through the skull and scalp, while maintaining an impressive sub-10 $\mu \mathrm{m}$ resolution at a $2 \mathrm{~mm}$ depth. [37] Another example is in vivo tracking of $\mathrm{Ag}_{2} \mathrm{~S}$ QD-labeled cells. The absence of autofluorescence led to a low detection limit ( $<1000$ cells) and allowed tracking these cells for up to 30 days. [46] 


\begin{tabular}{|c|c|c|c|c|}
\hline Compound & Size $(n m)$ & QY (\%) & Emission & Ref \\
\hline \multicolumn{5}{|c|}{ NIR I nanoprobes } \\
\hline $\begin{array}{l}\text { Quantum dots } \\
\text { (Culn(S/Se })_{2}, \ln P \\
\text { InAs, Ag2S, Si) }\end{array}$ & $2-10$ & $10-40$ & $\begin{array}{l}\text { Tunable from } 700 \text { to } \\
\qquad 1000 \mathrm{~nm} \\
\text { FWHM } 80-150 \mathrm{~nm}\end{array}$ & [8-18] \\
\hline Gold clusters & $\approx 1.5$ & $\approx 3$ & $\begin{array}{c}700-800 \mathrm{~nm} \\
\text { FWHM 100-150 nm }\end{array}$ & [19-22] \\
\hline Nanodiamonds & $20-100$ & $\approx 100$ & $\begin{array}{c}700 \mathrm{~nm} \\
\text { FWHM 100-150 nm }\end{array}$ & {$[23,24]$} \\
\hline Rare earth doped & $5 \ldots 200$ & $5-15$ & & {$[25,26,47]$} \\
\hline \multicolumn{5}{|c|}{ NIR II nanoprobes } \\
\hline Carbon nanotubes & $\begin{array}{c}\varnothing \approx 1 \\
L \approx 100-1000\end{array}$ & $<1$ & $\begin{array}{l}\text { Multiple broad peaks } \\
1000-1350 \mathrm{~nm}\end{array}$ & {$[37-40]$} \\
\hline $\begin{array}{l}\text { Quantum dots } \\
\left(\mathrm{Ag}_{2} \mathrm{~S}, \mathrm{Ag}_{2} \mathrm{Se}\right)\end{array}$ & $2-7$ & $10-15$ & $\begin{array}{l}\text { Tunable from } 1000 \text { to } \\
1350 \mathrm{~nm} \\
\text { FWHM } 30-200 \mathrm{~nm}\end{array}$ & {$[18,42-45]$} \\
\hline Rare earth doped & $10-12$ & $\leq 1$ & $\begin{array}{l}\approx 1200 \mathrm{~nm} ; \approx 1300 \mathrm{~nm} ; \\
\approx 1500 \mathrm{~nm} \\
\text { FWHM } 50-100 \mathrm{~nm}\end{array}$ & [41] \\
\hline
\end{tabular}

Table 1. Water soluble near infrared emitting nanoprobes, their respective size, $Q Y$ and emission wavelength. (For RE-NPs, QY is defined for standard one photon excitation, down-conversion fluorescence). 

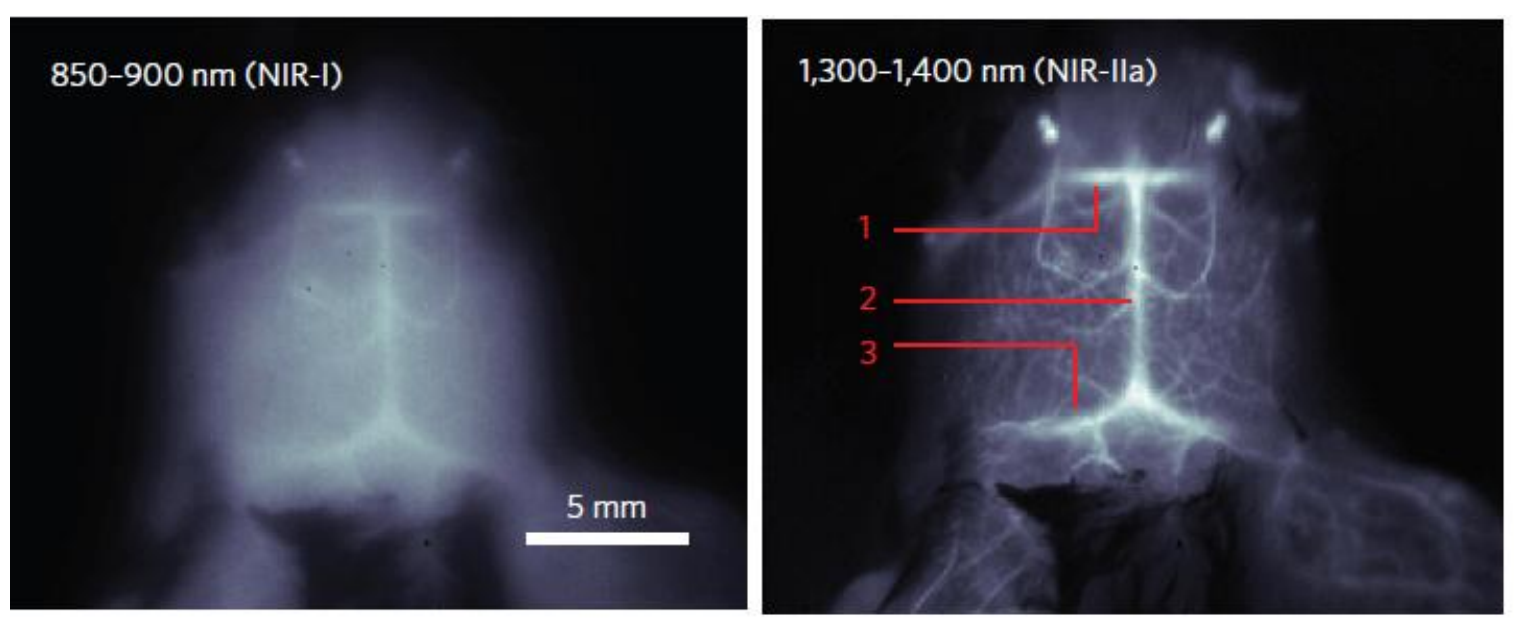

Figure 1. In vivo through-skull fluorescence imaging of the brain vasculature using SWNT injected in the tail vein, in the NIR I (left) and NIR II (right) range. (Reproduced from ref. [37••] with permission from Macmillan Publishers Ltd.).

\section{Nonlinear excitation/Upconversion}

Most inorganic nanoparticles present higher nonlinear absorption cross sections compared to organic fluorophores. Nonlinear excitation in the NIR enables deep penetration and reduces autofluorescence, thus leading to improved signal-to-background ratio. W. Webb and co-workers demonstrated that 2-photon excitation (2PE) is particularly suited to CdSe quantum dots (QDs) because they have 2-photon absorption cross sections two to three orders of magnitude higher than organic fluorophores, enabling dynamic observation of QDs through the skin of living mice, in capillaries hundred of micrometers deep. [27•]. However, 2PE requires expensive equipment and is better suited for cellular scale than for whole animal imaging where efficient focusing is hard to achieve deep in the tissues. For the latter application, rare-earth doped nanoparticles present the great advantage of being easily and efficiently excited in the near infrared with a continuous laser source by up conversion. [25] The large blue spectral shift between excitation and emission thus obtained and their high resistance to photobleaching contributes to enhance the detection sensitivity of up-conversion nanoparticles (UCNP). Lim et al. demonstrated first in vivo imaging using 50 to 200 $\mathrm{nm}$ lanthanide doped NPs in Caenorhabditis elegans (see figure 2a). [35] Since then, lanthanide doped NPs have been efficiently detected when injected deep in a rat and have allowed tracking cells in live animals. [28] Vinogradov and co-workers reported the use of UCNP doped with both $\mathrm{Yb}^{3+}$ and $\mathrm{Er}^{3+}$ to acquire vascular images with high contrast and resolution up to 340 microns deep into a mouse brain (see figure 2B). [48] To enhance the depth of in vivo imaging, further works focused on the synthesis of biocompatible NIR-to-NIR up conversion nanoparticles. [49] Within lanthanides, $\mathrm{Tm}^{3+}$ ions are thus especially well suited because they provide a main up conversion emission band around $800 \mathrm{~nm}$. Prasad et al. recently reported the development of core/shell NIR-to-NIR UCNP with enhanced up conversion efficiency, which enable whole body mice imaging with high signal to background ratio (see figure $2 \mathrm{C}$ ). [26] 

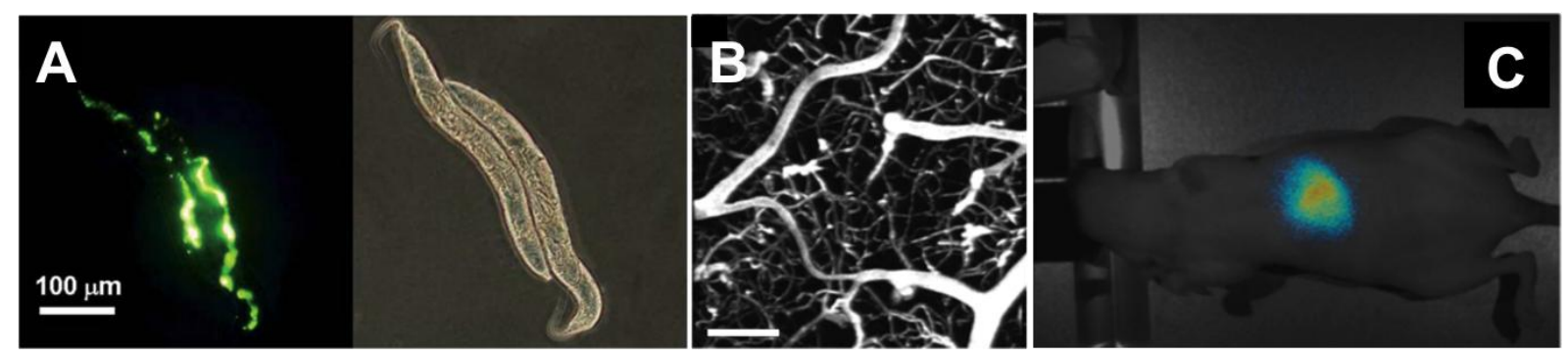

Figure 2: Up-conversion nanoparticles imaged in live organisms: A) Fluorescent and bright field images of $C$. elegans $\mathrm{NaYF}_{4}$ : Yb,Er@PEI nanoparticles; B) Maximal intensity projection image of a $200-\mu \mathrm{m}$-thick image stack showing vasculature in the mouse brain. Scale bar is $100 \mu \mathrm{m}$ (Reproduced from [48••] with permission from the National Academy of Sciences); C) Whole-body imaging of a nude mouse injected via tail vein with NIR-to-NIR core-shell nanoparticles. (Reproduced from ref. [26•] with permission from the American Chemical Society).

\section{Time gated detection}

In order to improve detection sensitivity, the signal of interest can be discriminated from the autofluorescence background spectrally (as mentioned above by selecting NIR excited and/or emitting NPs), but also temporally. This can be easily achieved using inorganic NPs that present slow fluorescence decay (from $10 \mathrm{~ns}$ to several $\mu \mathrm{s}$ ) compared to both extrinsic and intrinsic organic chromophores (a few ns). [5]

In the last decade, two techniques have emerged to perform time-gated detection using pulsed excitation. Time Correlated Single Photon Counting (TCSPC) provides a high temporal resolution with a pixel scanning acquisition. Fluorescence decay maps are then reconstructed from the raw data. This technique thus provides information on the distribution of fluorescence lifetimes, from which the slow NP decay can be deconvoluted from the fast autofluorescence. However, it can detect at most one fluorescence photon per pulse which limits the acquisition speed. It is therefore not well suited for dynamic sample imaging. In contrast, intensified gated cameras (iCCD) directly provide an integrated image for different controllable delays between the excitation and the detection window. Selecting a detection delay longer than the autofluorescence lifetime ensures its rejection, while efficiently detecting the signal from slower decaying NPs. Time-gated detection is particularly interesting to increase NP detection sensitivity in vivo, and several applications have been demonstrated for tumor targeting or cell tracking as illustrated in Table 2 and Figure 3. Finally, in order to completely overcome autofluorescence, le Masne de Chermont et al. have developed persistent luminescence nanoparticles that can be excited before the in vivo injection and followed for up to one hour without the need of an external illumination source. [50] 


\begin{tabular}{|c|c|c|c|c|c|}
\hline Probe type & $\begin{array}{l}\text { Probe lifetime } \\
\text { component }\end{array}$ & $\begin{array}{l}\text { Imaging system } \\
\text { Excitation / } \\
\text { Repetition rate } \\
\text { Detection }\end{array}$ & Sample & $\begin{array}{l}\text { Detection } \\
\text { enhancement }\end{array}$ & Ref \\
\hline $\begin{array}{l}\text { Silanized } \\
\text { CdSe QDs } \\
\lambda_{\text {em }}=575 \mathrm{~nm}\end{array}$ & $\begin{array}{l}2(11 \%) \\
8(49 \%) \\
24(40 \%)\end{array}$ & $\begin{array}{l}\text { Confocal microscopy } \\
5 \mathrm{MHz} \text { Ti:sapphire } \\
\text { laser TCSPC }\end{array}$ & $\begin{array}{l}\text { In vitro 3T3 } \\
\text { mouse fixed } \\
\text { fibroblasts }\end{array}$ & X 15 & [51] \\
\hline $\begin{array}{l}\text { NIR QDs } \\
\lambda_{\text {em }}=705 \mathrm{~nm}\end{array}$ & $>20 \mathrm{~ns}$ & $\begin{array}{l}\text { Wide-field imaging } \\
2 \mathrm{MHz} 630-\mathrm{nm} \text {-LED } \\
\text { iCCD }\end{array}$ & $\begin{array}{l}\text { In vivo. } \\
\text { Subcutaneous QD } \\
\text { injection }\end{array}$ & X 10 & [52] \\
\hline $\begin{array}{l}\text { NIR QDs } \\
\lambda_{\text {em }}=800 \mathrm{~nm}\end{array}$ & $150 \mathrm{~ns}$ & $\begin{array}{l}\text { Wide field } \\
\text { microscopy } \\
5 \mathrm{MHz} 659-\mathrm{nm} \text {-LED } \\
\text { iCCD }\end{array}$ & $\begin{array}{l}\text { Ex vivo. QD- } \\
\text { labeled cell on an } \\
\text { autofluorescent } \\
\text { tissue }\end{array}$ & $\times 25$ & [53] \\
\hline $\begin{array}{l}\text { Silicon QDs } \\
\lambda_{\mathrm{em}}=800 \mathrm{~nm}\end{array}$ & $5-13 \mu \mathrm{s}$ & $\begin{array}{l}\text { Fluorescence } \\
\text { tomography } \\
\text { 40MHz 470-nm laser } \\
\text { TCSPC }\end{array}$ & $\begin{array}{l}\text { In vivo. QD- } \\
\text { labeled cancer } \\
\text { cells injected in a } \\
\text { mouse }\end{array}$ & $\times 20$ & [54] \\
\hline
\end{tabular}

Table 2. Applications of time-gated detection for biological imaging. Detection enhancement stands for the gain in sensitivity or signal-to-background ratio between a time-gated and an ungated detection. 


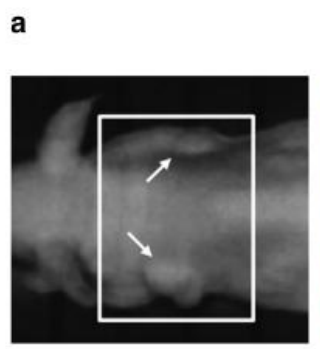

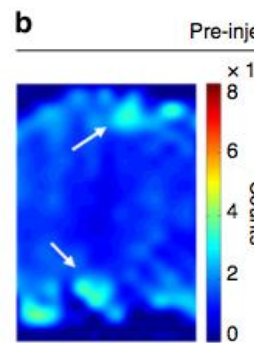

CW image re-injection

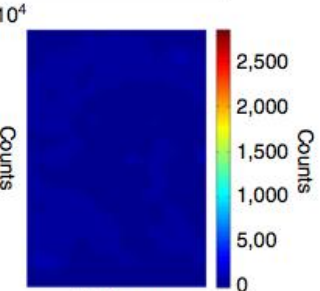

TG image

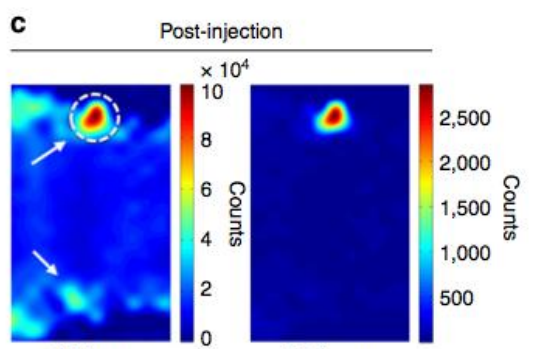

TG image

Figure 3: Continuous Wave (CW) and Time-Gated fluorescence images of tumors after injection of NIR luminescent nanoparticles made of porous silicon coated with $5 \mathrm{kDa}$ polyethylene glycol into the right shoulder tumor. (Reproduced from ref [54] with permission from Macmillan Publishers Ltd).

Another way to extract a signal of interest from the autofluorescence background is to use a specific modulation of the fluorescence intensity. NDs fluorescence, for example, depends on the spin properties of their ground state, and can therefore be modulated by an external magnetic field or a microwave irradiation. Since autofluorescence is insensitive to these modulations, the signal from NDs can be extracted with an excellent signal to noise ratio. $[55,56]$

\section{Multimodal imaging}

The interest of fluorescence in vivo imaging resides in its high sensitivity and spatial and temporal resolution. However, it is still limited to surface tissues; it is not quantitative and often requires additional information on anatomic environment. These limitations can be circumvented by combining fluorescence with other imaging modalities. For example, magnetic resonance imaging (MRI) and computed X-ray tomography (CT) provide whole body images and can be used for preoperative detection while fluorescence can be used intra-operatively for guided surgery. Positron emission tomography (PET) and single-photon emission computed tomography (SPECT) are very sensitive methods and can provide quantitative information on metabolic activity but suffer from a poor spatial resolution whereas fluorescence possesses a high spatial resolution but is not a quantitative technique. The combination of these modalities with fluorescence imaging can be achieved using nanoparticle-based multimodal probes.

A first strategy consists in coating the surface of fluorescent nanoparticles with active ligands. This method is quite universal as it only requires changing one part of the ligand. For example, the grafting of gadolinium complexes leads to dual MR-fluorescence imaging probes. [57] This method was also used to produce SPECT/fluorescence and PET/fluorescence imaging by grafting ${ }^{111} \mathrm{In}$ - and ${ }^{64} \mathrm{Cu}$-complexes respectively. [58] Unfortunately, such probes lack stability due to a non-covalent grafting of such these ligands.

Another strategy consists in incorporating different types of nanoparticles in a carrier nanoparticle. Such composite nanoparticles for fluorescence and MRI were obtained by incorporating QDs and superparamagnetic iron oxide nanoparticles (SPIONs) in silica or polymer matrices. [59] This method provides very stable probes and preserves the individual properties of each nanoparticle. However their use is limited by their generally larger size (typically a few hundreds of nanometers).

Alternatively, the doping of fluorescent nanoparticles with paramagnetic ions or radioactive nuclide is an effective method to obtain small and stable multimodal probes. The main drawback of this 
method is the limited amount of doping ions successfully incorporated. In the case of RE-NPs, the incorporation (either as component of the host matrix or as codopant) of different ions can be used to implement new modalities: $\mathrm{Gd}^{3+}$ for MRI and CT and ${ }^{18} \mathrm{~F}$ for PET [25]. The same strategy has been used with quantum dots, mainly by incorporating $\mathrm{Mn}^{2+}$ ions to produce bimodal MR/fluorescent probes. For example, Sitbon et al have shown that $\mathrm{Zn}-\mathrm{Cu}-\mathrm{In}-\mathrm{Se} / \mathrm{Zn}_{0.9} \mathrm{Mn}_{0.1} \mathrm{~S}$ QDs can be used to detect regional lymph nodes in both MRI and NIR fluorescence imaging (Fig. 4). [60] More recently, the incorporation of $64 \mathrm{Cu}$ by cation exchange enable their use as PET/fluorescence contrast agents [61].
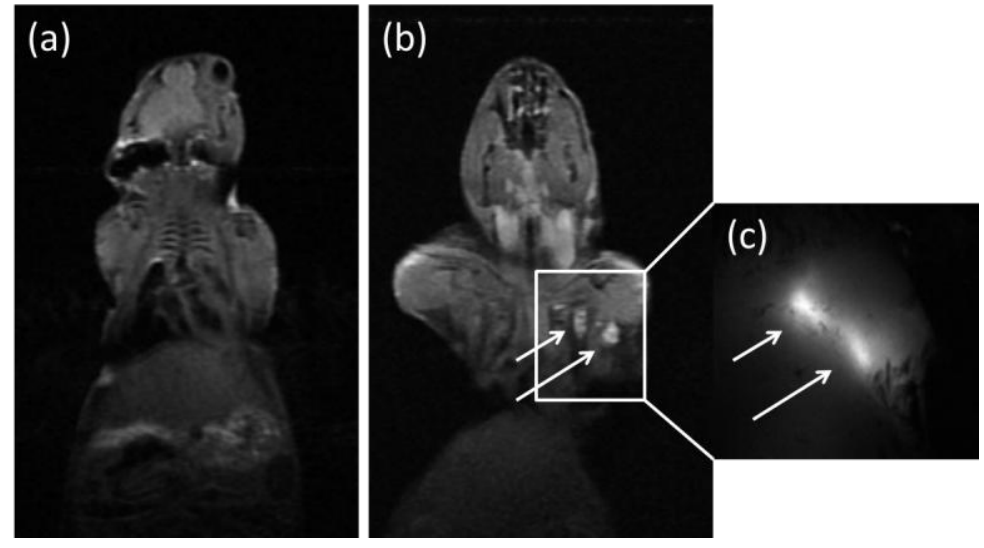

Figure 4. MR/fluorescence colocalization of regional lymph nodes with $\mathrm{Zn}$-Cu-In-Se/Zn $\mathrm{n}_{0.9} \mathrm{Mn}_{0.1} \mathrm{~S}$ QDs. T1-weighted MRI images of a mouse before (a) and after (b) injection of QDs and the corresponding NIR fluorescence image (c) (Reproduced from ref [60] with permission from the Royal Society of Chemistry)

Another way to obtain multimodal probes is to grow directly a nanoparticle on top of another one. This method provides very stable probes but some charge transfer between the different materials may cause a diminution of QY. This system has been particularly studied for the synthesis of $\mathrm{MR} /$ fluorescent probes, as for example in the $\mathrm{FePt} / \mathrm{CdSe}$ or $\mathrm{Fe}_{3} \mathrm{O}_{4} / \mathrm{CdSe}$ systems and more recently in the $\mathrm{Si} / \mathrm{Fe}_{3} \mathrm{O}_{4}$ system. $[59,62]$

\section{Conclusions/Perspectives}

Inorganic nanoprobes present unique optical properties that can be harnessed to enhance the sensitivity, resolution and imaging depth of fluorescence in vivo imaging. They are therefore bound to play an increasingly central role in the development of new imaging techniques and applications. Continuing progress in the synthesis of these NPs and in the control and understanding of their optical properties, together with the development of adapted instrumentation, should further improve their imaging performance. To translate these advances into pertinent bio-applications, the development of their surface chemistry is also required, in order to better control their biodistribution and improve their targeting efficiency. This should in turn enable a better understanding and control of their potential toxicity. Ultimately, fast clearance of these NPs from the body will be required to bring these imaging modalities to the clinical field. We note some recent progress in this direction, with examples of fluorescent NPs that are either small enough [31] or degrade into molecular compounds [54] to undergo partial renal clearance. Future expected developments should also include smart nanoprobes that are able to report on their biochemical environment, or theranostics probes that use local heating, singlet oxygen production or controlled drug delivery as a therapeutic tool in addition to imaging. 


\section{References:}

1. J.V. Frangioni, In vivo near-infrared fluorescence imaging, Curr Opin Chem Biol 7, 2003, 626-634.

2. J.O. Escobedo, O. Rusin, S. Lim and R.M. Strongin, NIR dyes for bioimaging applications, Curr Opin Chem Biol 14, 2010, 64-70.

3. S.A. Hilderbrand and R. Weissleder, Near-infrared fluorescence: application to in vivo molecular imaging, Curr Opin Chem Biol 14, 2010, 71-79.

4. A.L. Vahrmeijer, M. Hutteman, J.R. van der Vorst, C.J.H. van de Velde and J.V. Frangioni, Imageguided cancer surgery using near-infrared fluorescence, Nat Rev Clin Oncol 10, 2013, 507-518.

5. R. Richards-Kortum and E. Sevick-Muraca, Quantitative optical spectroscopy for tissue diagnosis, Ann Rev Phys Chem 47, 1996, 555-606.

6. J.S. Slakter, L.A. Yannuzzi, D.R. Guyer, J.A. Sorenson and D.A. Orlock, Indocyanine-green angiography, Curr Opin Ophthalmol 6, 1995, 25-32.

7. E. Cassette, M. Helle, L. Bezdetnaya, F. Marchal, B. Dubertret and T. Pons, Design of new quantum dot materials for deep tissue infrared imaging, Adv Drug Deliv Rev 65, 2013, 719-731.

8. E. Cassette, T. Pons, C. Bouet, M. Helle, L. Bezdetnaya, F. Marchal and B. Dubertret, Synthesis and characterization of near-Infrared $\mathrm{Cu}-\mathrm{In}-\mathrm{Se} / \mathrm{ZnS}$ core/shell quantum dots for in vivo imaging, Chem Mater 22, 2010, 6117-6124.

9. L. Li, T.J. Daou, I. Texier, T.T. Kim Chi, N.Q. Liem and P. Reiss, Highly luminescent $\mathrm{CulnS}_{2} / \mathrm{ZnS}$ core/shell nanocrystals: cadmium-free quantum dots for in vivo imaging, Chem Mater 21, 2009, 2422-2429.

10. T. Pons, E. Pic, N. Lequeux, E. Cassette, L. Bezdetnaya, F. Guillemin, F. Marchal and B. Dubertret, Cadmium-free $\mathrm{CulnS}_{2} / \mathrm{ZnS}$ quantum dots for sentinel lymph node imaging with reduced toxicity, ACS Nano 4, 2010, 2531-2538.

11. R. Xie, M. Rutherford and X. Peng, Formation of high-quality I-III-VI semiconductor nanocrystals by tuning relative reactivity of cationic precursors, J Am Chem Soc 131, 2009, 5691-5697.

12. R. Xie and X. Peng, Synthesis of Cu-doped InP nanocrystals (d-dots) with ZnSe diffusion barrier as efficient and color-tunable NIR emitters, J Am Chem Soc 131, 2009, 10645-10651.

13. A. Aharoni, T. Mokari, I. Popov and U. Banin, Synthesis of InAs $/ \mathrm{CdSe} / \mathrm{ZnSe}$ Core $/ \mathrm{Shell}_{1} / \mathrm{Shell}_{2}$ structures with bright and stable near-infrared fluorescence, J Am Chem Soc 128, 2005, 257-264.

14. J. Gao, K. Chen, R. Xie, J. Xie, S. Lee, Z. Cheng, X. Peng and X. Chen, Ultrasmall near-infrared noncadmium quantum dots for in vivo tumor imaging, Small 6, 2010, 256-261.

15. S.-W. Kim, J.P. Zimmer, S. Ohnishi, J.B. Tracy, J.V. Frangioni and M.G. Bawendi, Engineering InAs $\mathrm{P}_{1-\mathrm{x}} / \mathrm{InP} / \mathrm{ZnSe} \mathrm{III}-\mathrm{V}$ alloyed core/shell quantum dots for the near-infrared, J Am Chem Soc 127, 2005, 10526-10532.

16. J.P. Zimmer, S.-W. Kim, S. Ohnishi, E. Tanaka, J.V. Frangioni and M.G. Bawendi, Size series of small indium arsenide-zinc selenide core-shell nanocrystals and their application to in vivo imaging, J Am Chem Soc 128, 2006, 2526-2527.

17. H. Chen, B. Li, M. Zhang, K. Sun, Y. Wang, K. Peng, M. Ao, Y. Guo and Y. Gu, Characterization of tumor-targeting Ag2S quantum dots for cancer imaging and therapy in vivo, Nanoscale 6, 2014, 12580-12590.

18. Y.P. Du, B. Xu, T. Fu, M. Cai, F. Li, Y. Zhang and Q.B. Wang, Near-infrared photoluminescent $\mathrm{Ag}_{2} \mathrm{~S}$ quantum dots from a single source precursor, J Am Chem Soc 132, 2010, 1470-1471.

19. F. Aldeek, M.A.H. Muhammed, G. Palui, N. Zhan and H. Mattoussi, Growth of highly fluorescent polyethylene glycol- and zwitterion-functionalized gold nanoclusters, ACS Nano 7, 2013, 2509-2521.

20. H. Chen, S. Li, B. Li, X. Ren, S. Li, D.M. Mahounga, S. Cui, Y. Gu and S. Achilefu, Folate-modified gold nanoclusters as near-infrared fluorescent probes for tumor imaging and therapy, Nanoscale 4, 2012, 6050-6064.

21. J. Xie, Y. Zheng and J.Y. Ying, Protein-directed synthesis of highly fluorescent gold nanoclusters, J Am Chem Soc 131, 2009, 888-889. 
22. X. Yuan, Z.T. Luo, Q.B. Zhang, X.H. Zhang, Y.G. Zheng, J.Y. Lee and J.P. Xie, Synthesis of highly fluorescent metal $(\mathrm{Ag}, \mathrm{Au}, \mathrm{Pt}$, and $\mathrm{Cu})$ nanoclusters by electrostatically induced reversible phase transfer, ACS Nano 5, 2011, 8800-8808.

23. C.-C. Fu, H.-Y. Lee, K. Chen, T.-S. Lim, H.-Y. Wu, P.-K. Lin, P.-K. Wei, P.-H. Tsao, H.-C. Chang and W. Fann, Characterization and application of single fluorescent nanodiamonds as cellular biomarkers, Proc Natl Acad Sci USA 104, 2007, 727-732.

24. Y.-R. Chang, H.-Y. Lee, K. Chen, C.-C. Chang, D.-S. Tsai, C.-C. Fu, T.-S. Lim, Y.-K. Tzeng, C.-Y. Fang, C.-C. Han, et al., Mass production and dynamic imaging of fluorescent nanodiamonds, Nat Nano 3, 2008, 284-288.

25. G. Chen, H. Qiu, P.N. Prasad and X. Chen, Upconversion nanoparticles: design, nanochemistry, and applications in theranostics, Chem Rev 114, 2014, 5161-5214.

26•. J.A. Damasco, G. Chen, W. Shao, H. Ågren, H. Huang, W. Song, J.F. Lovell and P.N. Prasad, Sizetunable and monodisperse Tm3+/Gd3+-doped hexagonal NaYbF4 nanoparticles with engineered efficient near infrared-to-near infrared upconversion for in vivo imaging, ACS Appl Mater Interfaces 6, 2014, 13884-13893.

Detailed description and characterization of new bright NIR-to-NIR core--shell up conversion nanoparticles and demonstration of their use for whole body mouse imaging.

27•. D.R. Larson, W.R. Zipfel, R.M. Williams, S.W. Clark, M.P. Bruchez, F.W. Wise and W.W. Webb, Water-soluble quantum dots for multiphoton fluorescence imaging in vivo, Science 300, 2003, 14341436.

CdSe-based QDs were shown to possess 2PE cross -sections two to three orders of magnitude larger than organic dyes. QDs were used for 2PE imaging of the mouse brain vasculature.

28. N.M. Idris, Z. Li, L. Ye, E.K.W. Sim, R. Mahendran, P.C.-L. Ho and Y. Zhang, Tracking transplanted cells in live animal using upconversion fluorescent nanoparticles, Biomaterials 30, 2009, 5104-5113.

29•. T.-J. Wu, Y.-K. Tzeng, W.-W. Chang, C.-A. Cheng, Y. Kuo, C.-H. Chien, H.-C. Chang and J. Yu, Tracking the engraftment and regenerative capabilities of transplanted lung stem cells using fluorescent nanodiamonds, Nat Nano 8, 2013, 682-689.

NDs were used to label stem/progenitor stem cells and follow their biodistribution in vivo without impairing their regenerative capabilities for up to 7 days after intraveneous transplantation.

30. B. Dubertret, P. Skourides, D.J. Norris, V. Noireaux, A.H. Brivanlou and A. Libchaber, In vivo imaging of quantum dots encapsulated in phospholipid micelles, Science 298, 2002, 1759-1762.

31. H.S. Choi, W. Liu, P. Misra, E. Tanaka, J.P. Zimmer, B.I. Ipe, M.G. Bawendi and J.V. Frangioni, Renal clearance of quantum dots, Nat Biotechnol 25, 2007, 1165-1170.

32. Y. Matsumura and $H$. Maeda, A new concept for macromolecular therapeutics in cancer chemotherapy: mechanism of tumoritropic accumulation of proteins and the antitumor agent smancs, Cancer Res 46, 1986, 6387-6392.

33. L. Tang, X. Yang, Q. Yin, K. Cai, H. Wang, I. Chaudhury, C. Yao, Q. Zhou, M. Kwon, J.A. Hartman, et al., Investigating the optimal size of anticancer nanomedicine, Proc Natl Acad Sci US S A 111, 2014, 15344-15349.

34. C.-Y. Fang, V. Vaijayanthimala, C.-A. Cheng, S.-H. Yeh, C.-F. Chang, C.-L. Li and H.-C. Chang, The exocytosis of fluorescent nanodiamond and its use as a long-term cell tracker, Small 7, 2011, 33633370.

35. Y. Lim, S. Kim, A. Nakayama, N. Stott and M.J.V.F. Bawendi, Selection of quantum dot wavelengths for biomedical assays and imaging, Mol Imaging 2, 2003, 50-54.

36. Z.M. Tao, G.S. Hong, C. Shinji, C.X. Chen, S. Diao, A.L. Antaris, B. Zhang, Y.P. Zou and H.J. Dai, Biological imaging using nanoparticles of small organic molecules with fluorescence emission at wavelengths longer than 1000 nm, Angew Chem Int Ed 52, 2013, 13002-13006.

37••. G. Hong, S. Diao, J. Chang, A.L. Antaris, C. Chen, B. Zhang, S. Zhao, D.N. Atochin, P.L. Huang, K.I. Andreasson, et al., Through-skull fluorescence imaging of the brain in a new near-infrared window, Nat Photon 8, 2014, 723-730.

SWNTs were used as NIR II emitters to demonstrate through-skull imaging of the mouse brain vasculature. A spatial resolution of less than $10 \mu \mathrm{m}$ was preserved to a depth of more than $2 \mathrm{~mm}$. 
38. K. Welsher, S.P. Sherlock and H.J. Dai, Deep-tissue anatomical imaging of mice using carbon nanotube fluorophores in the second near-infrared window, Proc Natl Acad Sci U S A 108, 2011, 8943-8948.

39. G.S. Hong, J.C. Lee, J.T. Robinson, U. Raaz, L.M. Xie, N.F. Huang, J.P. Cooke and H.J. Dai, Multifunctional in vivo vascular imaging using near-infrared II fluorescence, Nat Med 18, 2012, 18411849.

40. K. Welsher, Z. Liu, S.P. Sherlock, J.T. Robinson, Z. Chen, D. Daranciang and H.J. Dai, A route to brightly fluorescent carbon nanotubes for near-infrared imaging in mice, Nat Nanotechnol 4, 2009, 773-780.

41. D.J. Naczynski, M.C. Tan, M. Zevon, B. Wall, J. Kohl, A. Kulesa, S. Chen, C.M. Roth, R.E. Riman and P.V. Moghe, Rare-earth-doped biological composites as in vivo shortwave infrared reporters, Nat Commun 4, 2013, 2199.

42•. G. Hong, J.T. Robinson, Y. Zhang, S. Diao, A.L. Antaris, Q. Wang and H. Dai, In vivo fluorescence imaging with $\mathrm{Ag}_{2} \mathrm{~S}$ quantum dots in the second near-infrared region, Angew Chem Int Ed 51, 2012, 9818-9821.

NIR II $\mathrm{Ag}_{2} \mathrm{~S}$ QDs were synthesized with $15 \%$ QY and used for tumor detection and deep inner organ imaging in vivo in mice.

43. Y. Zhang, G.S. Hong, Y.J. Zhang, G.C. Chen, F. Li, H.J. Dai and Q.B. Wang, $\mathrm{Ag}_{2} \mathrm{~S}$ quantum dot: a bright and biocompatible fluorescent nanoprobe in the second near-infrared window, ACS Nano 6, 2012, 3695-3702.

44. B. Dong, C. Li, G. Chen, Y. Zhang, Y. Zhang, M. Deng and Q. Wang, Facile synthesis of highly photoluminescent $\mathrm{Ag}_{2} \mathrm{Se}$ quantum dots as a new fluorescent probe in the second near-infrared window for in vivo imaging, Chem Mater 25, 2013, 2503-2509.

45. C.-N. Zhu, P. Jiang, Z.-L. Zhang, D.-L. Zhu, Z.-Q. Tian and D.-W. Pang, $\mathrm{Ag}_{2}$ Se quantum dots with tunable emission in the second near-infrared window, ACS Appl Mater Interfaces 5, 2013, 11861189.

46. G.C. Chen, F. Tian, Y. Zhang, Y.J. Zhang, C.Y. Li and Q.B. Wang, Tracking of transplanted human mesenchymal stem cells in living mice using near-infrared $\mathrm{Ag}_{2} \mathrm{~S}$ quantum dots, Adv Funct Mater 24, 2014, 2481-2488.

47. M. Pokhrel, L.C. Mimun, B. Yust, G.A. Kumar, A. Dhanale, L. Tang and D.K. Sardar, Stokes emission in GdF3:Nd3+ nanoparticles for bioimaging probes, Nanoscale 6, 2014, 1667-1674.

48••. T.V. Esipova, X. Ye, J.E. Collins, S. Sakadzic, E.T. Mandeville, C.B. Murray and S.A. Vinogradov, Dendritic upconverting nanoparticles enable in vivo multiphoton microscopy with low-power continuous wave sources, Proc Natl Acad Sci U S A 109, 2012, 20826-20831.

This article demonstrates that dendrimer-bound up-conversion NPs are photostable and biocompatible, and enable in vivo mapping of the cortical vasculature down to $400 \mu \mathrm{m}$ under the tissue surface with a continuous wave excitation.

49. L. Xiong, T. Yang, Y. Yang, C. Xu and F. Li, Long-term in vivo biodistribution imaging and toxicity of polyacrylic acid-coated upconversion nanophosphors, Biomaterials 31, 2010, 7078-7085.

50. Q.L. de Chermont, C. Chaneac, J. Seguin, F. Pelle, S. Maitrejean, J.P. Jolivet, D. Gourier, M. Bessodes and D. Scherman, Nanoprobes with near-infrared persistent luminescence for in vivo imaging, Proc Natl Acad Sci U S A 104, 2007, 9266-9271.

51. M. Dahan, T. Laurence, F. Pinaud and D.S. Chemla, Time-gated biological imaging by use of colloidal quantum dots, Opt Lett 26, 2001, 825-827.

52. A. May, S. Bhaumik, S.S. Gambhir, C. Zhan and S. Yazdanfar, Whole-body, real-time preclinical imaging of quantum dot fluorescence with time-gated detection, J Biomed Opt 14, 2009, 060504.

53. S. Bouccara, A. Fragola, E. Giovanelli, G. Sitbon, N. Lequeux, T. Pons and V. Loriette, Time-gated cell imaging using long lifetime near-infrared-emitting quantum dots for autofluorescence rejection, $J$ Biomed Opt 19, 2014, 051208.

54••. L. Gu, D.J. Hall, Z. Qin, E. Anglin, J. Joo, D.J. Mooney, S.B. Howell and M.J. Sailor, In vivo timegated fluorescence imaging with biodegradable luminescent porous silicon nanoparticles, Nat Commun 4, 2013, 2326. 
This article demonstrates a significant in vivo detection enhancement of silicon nanoparticles using time-gated imaging. The authors also show that these nanoparticles present a low toxicity thanks to an effective renal clearance.

55. R. Igarashi, Y. Yoshinari, H. Yokota, T. Sugi, F. Sugihara, K. Ikeda, H. Sumiya, S. Tsuji, I. Mori, H. Tochio, et al., Real-time background-free selective imaging of fluorescent nanodiamonds in vivo, Nano Lett 12, 2012, 5726-5732.

56. S.K. Sarkar, A. Bumb, X.F. Wu, K.A. Sochacki, P. Kellman, M.W. Brechbiel and K.C. Neuman, Widefield in vivo background free imaging by selective magnetic modulation of nanodiamond fluorescence, Biomed Opt Express 5, 2014, 1190-1202.

57. J. Kim, Y. Piao and T. Hyeon, Multifunctional nanostructured materials for multimodal imaging, and simultaneous imaging and therapy, Chem Soc Rev 38, 2009, 372-390.

58. Y. Xing, J. Zhao, P.S. Conti and K. Chen, Radiolabeled nanoparticles for multimodality tumor imaging, Theranostics 4, 2014, 290-306.

59. N.C. Bigall, W.J. Parak and D. Dorfs, Fluorescent, magnetic and plasmonic-hybrid multifunctional colloidal nano objects, Nano Today 7, 2012, 282-296.

60. G. Sitbon, S. Bouccara, M. Tasso, A. Francois, L. Bezdetnaya, F. Marchal, M. Beaumont and T. Pons, Multimodal Mn-doped I-III-VI quantum dots for near infrared fluorescence and magnetic resonance imaging: from synthesis to in vivo application, Nanoscale 6, 2014, 9264-9272.

61. X. Sun, X. Huang, J. Guo, W. Zhu, Y. Ding, G. Niu, A. Wang, D.O. Kiesewetter, Z.L. Wang, S. Sun, et al., Self-illuminating ${ }^{64} \mathrm{Cu}$-doped $\mathrm{CdSe} / \mathrm{ZnS}$ nanocrystals for in vivo tumor imaging, J Am Chem Soc 136, 2014, 1706-1709.

62. K. Sato, S. Yokosuka, Y. Takigami, K. Hirakuri, K. Fujioka, Y. Manome, H. Sukegawa, H. Iwai and N. Fukata, Size-tunable silicon/iron oxide hybrid nanoparticles with fluorescence, superparamagnetism, and biocompatibility, J Am Chem Soc 133, 2011, 18626-18633. 